\title{
A construção de sentidos pela Argumentação na Língua: blocos semânticos em um debate sobre o Estatuto da Família
}

\author{
Meaning construction by Argumentation in Language: semantic blocks in a debate on \\ the Family Statute
}

Marildo de Oliveira Lopes

Márcia Helena de Melo Pereira

Adilson Ventura da Silva

Universidade Estadual do Sudoeste da Bahia - UESB - Vitória da Conquista - Bahia - Brasil

\begin{abstract}
$\longrightarrow$
Resumo: Este artigo discute, por meio de uma análise linguística, a construção de sentidos possibilitada pelos encadeamentos argumentativos evocados nas falas de dois deputados, em um debate acerca do Estatuto da Família que objetiva restringir o conceito de família aos casais heterossexuais e filho (s). Essa análise se dá à luz da Teoria dos Blocos Semânticos (TBS), criada por Oswald Ducrot e Marion Carel (2005). A TBS defende que a argumentação está na própria língua e que discursos são evocados por meio de encadeamentos argumentativos - que são a combinação de dois segmentos de um enunciado, unidos pelos conectores PORTANTO (DC) e NO ENTANTO (PT), que estabelecem interdependência semântica entre os segmentos. Para atingir nosso propósito, transcrevemos o debate em questão, realizamos um estudo bibliográfico acerca do tema e prosseguimos com a análise do nosso corpus. Selecionamos dois excertos das falas de cada debatedor que melhor ilustram a evocação dos aspectos argumentativos. Nossos dados comprovam que a própria língua possui orientação argumentativa e que os sentidos são construídos a partir da argumentação. Além disso, confirmamos que a argumentação é materializada na relação entre entidades linguísticas.
\end{abstract}

Palavras-chave: argumentação na língua, construção de sentidos, blocos semânticos, encadeamentos argumentativos, interdependência semântica, aspectos argumentativos.

\begin{abstract}
This article aims to discuss, through a linguistic analysis, the construction of meaning made possible by argumentative predicates evoked in the speeches of two congressmen, in a debate on the Statute of the Family which aims to restrict the concept of family to heterosexual couples and their children. We performed our analysis in the light of the Semantic Blocks Theory (SBT), created by Oswald Ducrot and Marion Carel (2005). SBT supports that argumentation is in language and that discourses are evoked by argumentative predicates - which are sets of fragments linked by either a DC (therefore) or a PT (however) connector that creates semantic interdependence between the fragments. In order to achieve our goal, we transcribed the debate, conducted a bibliographic study on the topic and proceeded with the analysis of our corpus. We selected two excerpts from the speeches of each debater that best illustrate the evocation of argumentative aspects. Our data shows that language has argumentative orientation, building meaning. Moreover, we confirmed that argumentation is materialized in the relationship between linguistic entities.
\end{abstract}

Key-words: argumentation within language, meaning construction, semantic blocks, argumentative predicates, semantic interdependence, argumentative aspects. 


\section{Introdução'}

A partir da década de 1960 na França, diversos estudos linguísticos passaram a se interessar pelo sentido. No início dos anos 1970, ancorada na linguística de Ferdinand Saussure (2006), a Teoria da Argumentação na Língua (ANL) criada por Oswald Ducrot e Jean-Claude Anscombre (1983) - inicia uma longa e fascinante jornada no intuito de compreender como se dá a constituição de sentidos pela orientação argumentativa intrínseca ao próprio sistema linguístico.

Por muito tempo, a concepção tradicional da argumentação acreditava que argumentar era fornecer um fato lógico da realidade, que proporcionasse uma justificação para uma conclusão. Assim, a argumentação se encontrava na passagem do argumento para a conclusão. Contrapondo-se a essa concepção, Ducrot e Anscombre (1983), desde o início da ANL, defendem que a argumentação pode ser explicada na língua, apesar de que, segundo BEZ (2014), "em seu início, a ANL estava enraizada em princípios lógicos, como as condições de verdade e de falsidade, ancoradas à realidade, e apresentava como ferramentas de aplicação a pressuposição na descrição do sentido" (BEZ, 2014, p. 18). À medida em que a ANL foi se desenvolvendo, cada vez mais essa teoria passa a defender que as próprias palavras são argumentativas, portanto são elas que produzem a argumentação e não os "fatos lógicos".

Nesse sentido, Cabral (2011), ao se apropriar de Ducrot $(1994)^{2}$, Anscombre e Ducrot $(1997)^{3}$, Ducrot $(2001)^{4}$ e Carel $(2001)^{5}$, explica que a ANL "tal como a postularam Anscombre e Ducrot na década de 1980 e a desenvolvem atualmente Ducrot e Carel,

\footnotetext{
1 Uma versão resumida dessa investigação foi apresenta no ENELIN/2016, ocorrido na Universidade Federal do Maranhão UFMA.

2 DUCROT, O. Les topï dans la théorie de l'rgumentation dans la langue. In: Platin, C. (ed.). lieux communs, topoï, stéréotypes. Paris: Kimé, 1994, p. 233-248.

${ }^{3}$ ANSCOMBRE, J-C e DUCROT, O. L'argumentation dans la langue.Liège: Mardaga. 1997

${ }^{4}$ DUCROT, O. Critères Argumentatifs et Analyse Lexicale. In : Langages, 142 (Les discours intérieurs au lexique, sob a direção de A. H. Ibrahim) p. 22-40. Paris: Larousse, 2001.

5 CAREL, M. Argumentation interne et argumentation externe au lexique: des propriétés différentes. In : Langages, 142 (Les discours intérieurs au lexique, sob a direção de A. H. Ibrahim) p. 10-21. Paris: Larousse, 2001.
}

toma a palavra argumentação num sentido restrito à argumentação linguística" (CABRAL (2011, p. 207, grifos nossos). Portanto, a ANL tem como objetivo principal explicar como o sentido se constitui a partir do potencial argumentativo da própria língua.

Nessa empreitada, a ANL passa por diferentes fases, conforme explicaremos nesse artigo. É válido salientarmos que na terceira fase da teoria, ou seja, na teoria dos blocos semânticos (TBS), Ducrot e Carel (2005) chegam à fase mais expressiva da ANL. Bez (2014) diz que "[...] o objetivo [abordar a língua em seu sentido intralinguístico] somente foi alcançado em 2005 com a obra La Semántica Argumentativa. Una Introducción a la Teoría de los Bloques Semánticos e com a aplicação do conceito de blocos" (BEZ, 2014, p. 18, grifos nossos). Assim, foi na TBS, fase mais radical da $A N L$, que $O$ sentido intralinguístico ganhou total ênfase. Com a TBS, a semântica argumentativa procura mostrar que as entidades linguísticas produzem argumentação por si só. Para Carel e Ducrot (2005), nessa terceira fase, o sentido se constitui a partir dos encadeamentos argumentativos, na relação entre um segmento e outro, unidos por um conector. Para um encadeamento normativo, utiliza-se o conector PORTANTO (DC), enquanto para um encadeamento transgressivo utiliza-se o conector NO ENTANTO (PT), conforme exemplificaremos mais adiante. Esses conectores estabelecem uma interdependência semântica entre os segmentos linguísticos, fazendo com que um dependa do outro para completar seu sentido. Com base em Ducrot (2001) e Carel (2001) para explicar a origem das siglas $D C$ e $P T$, Cabral (2011) salienta que:

$\mathrm{Na}$ abordagem da Teoria dos Blocos Semânticos TBS, a argumentação é definida como um encadeamento de dois segmentos de discurso, eventualmente ligados por um conector. Desse ponto de vista, denomina-se normativa a argumentação cujos segmentos que a compõem mantêm entre si a mesma interdependência semântica que os segmentos ligados por logo (donc em francês); denomina-se transgressiva a argumentação cujos segmentos que a compõem mantêm entre si a mesma interdependência semântica que os segmentos ligados por entretanto (pourtant 
em francês) (CABRAL, 2011, p. 207-208, grifos nossos).

Em outras palavras, a sigla que representa 0 conector portanto, criando a argumentação normativa, é "DC", que tem origem na palavra francesa "donc", que significa "logo". Por outro lado, a sigla que representa o conector no entanto é "PT", que estabelece a argumentação transgressiva e que tem raízes na palavra francesa pourtant, que significa "entretanto" (é importante observarmos que pourtant não significa portanto, é um falso cognato). Alguns pesquisadores, como Bez (2014), entre outros, optam, em suas traduções, por reproduzirem as siglas idênticas ao francês, como nós também o fazemos neste artigo. Já outros pesquisadores brasileiros, para evitarem possíveis confusões nos leitores, preferem grafias mais próximas da língua portuguesa, como procede Cabral (2011), que explica o seguinte a este respeito:

Cumpre esclarecer uma decisão de tradução. Carel e Ducrot utilizam, na TBS, as sentenças $X$ DC $Y$ e $X$ PT $Y$ para representar os encadeamentos argumentativos. A fim de evitar confusões de leitura, optei por traduzir essas sentenças por X LG Y e X NE Y, em que os os conectores correspondentes a donc e pourtant em francês, respectivamente, foram substituídos, em português, por logo LG e no entanto NE, respectivamente. O motivo dessa opção encontra-se na possibilidade de confusão entre o conector pourtant, presente na fórmula original da TBS X PT $Y$ e cujo sentido é no entanto, e o conector portanto, que tem o sentido inverso de pourtant (CABRAL, 2011, p. 208, grifos nossos).

Tendo apontado alguns esclarecimentos relevantes acerca da TBS, pretendemos aprofundar nossa discussão sobre essa terceira fase da ANL com subsídios teóricos, com os quais embasaremos a análise de um corpus bastante favorável para a nossa investigação: um debate ${ }^{6}$ sobre o Estatuto da Família entre o Deputado Federal Ronaldo Fonseca, do Partido Republicano da Ordem Social (PROS), e o Deputado Federal Jean Wyllys, do Partido Socialismo e Liberdade (PSOL), então membros da Comissão especial do recém-aprovado Projeto de Lei - PL

${ }^{6}$ Esse debate foi apresentado pela TV Brasil em 07 de maio de 2014 e veiculado no portal Youtube, de onde fizemos o download do vídeo de duração de $12 \mathrm{~min}$.
6.583/13, que objetiva definir a família no Brasil como a união entre um homem, uma mulher e os filhos, excluindo várias outras configurações de família, como, por exemplo: mãe solteira e filho (s), avó e neto criado por ela, o poliamor, entre outros. debate entre os dois deputados concentra-se principalmente na união homoafetiva.

Schneuwly e Dolz (1999) e Cristóvão, Durão e Nascimento (2003) apontam as peculiaridades do gênero debate: tem cunho argumentativo e é poligerado, pois envolve, no mínimo, dois debatedores discutindo um tema controverso por meio de argumentos e contra-argumentos. Poderíamos, entretanto, ter escolhido um outro gênero para o nosso estudo, já que acreditamos ser a língua em si mesma possuidora de orientação argumentativa. Manifestamos interesse em estudos sobre o gênero debate, pois estamos desenvolvendo uma pesquisa de mestrado acerca desse gênero com alunos da Educação Básica. Assim, decidimos selecioná-lo como forma de ilustrar a força argumentativa das entidades linguísticas, não nos atendo, neste estudo, aos aspectos extralinguísticos do gênero.

Pretendemos utilizar excertos dos discursos dos deputados para ilustrar a formação de diferentes blocos semânticos que constroem sentidos diferentes. Esta análise pode nos ajudar a compreender o sentido desses discursos em pauta e a perceber as relações entre entidades linguísticas que produzem valor argumentativo e evocam discursos.

\section{Teoria da Argumentação na Língua}

Interessada pela linguística de base saussuriana, a ANL é a teoria que defende que a argumentação está inscrita no próprio sistema linguístico. Contudo, Carel e Ducrot (2005) esclarecem que a busca saussuriana era explicar a língua pela própria língua, e que a ANL busca explicar a língua pelo discurso (CAREL E DUCROT, 2005, p. 24). Outro ponto relevante nessa teoria, de acordo com os autores, é que a argumentação se relaciona intimamente com o sentido: "[...] a ideia fundamental 
sobre o sentido: o sentido tem base na argumentação" (CAREL E DUCROT, 2005, p. 12, tradução nossa) ${ }^{7}$. Portanto, ao nos apropriarmos desses autores, podemos dizer que a ANL é a teoria que defende que o sentido se constitui pela argumentação, que é intrínseca ao próprio sistema linguístico. Com base na explicação do conceito básico da ANL, prossigamos com o percurso histórico e as bases filosóficas dessa teoria.

A ANL foi criada por Jean-Claude Anscombre e por Oswald Ducrot (1983) no início da década de 70, opondo-se à concepção tradicional da argumentação. Segundo Ducrot (1988), nessa concepção tradicional, considerada por ele como "ingênua", um discurso é argumentativo se apresenta três condições: a primeira é a existência de dois segmentos: um argumento (A) e uma conclusão (C). A segunda condição é que $A$ possui um fato da realidade $(H)$, logo, A possui um valor de verdade ou de falsidade em si mesmo, independente de C. Para ilustrar isso, o autor traz um exemplo: "faz bom tempo, vamos passear", em que $A=$ faz bom tempo (contendo um fato da realidade) e $\mathrm{C}=$ vamos passar. Não há, nessa concepção, interdependência de sentido entre A e C. O sentido de A está completo, independente de $C$ (DUCROT, 1988, p. 72-73).

Contrapondo-se a essa concepção tradicional, Ducrot (1988, p. 73-74) apresenta dois exemplos para ilustrar porque um segmento A não está completo antes de C: 1- "faz calor, vamos passear" e 2- "faz calor, não vamos passear". Nesses exemplos, fica claro que o sentido de "faz calor" (A) não está completo, ele depende da conclusão (C) para ter sentido. $O$ valor semântico de $A$ no primeiro exemplo (bom tempo = boa oportunidade para passear) é completamente diferente do segundo (bom tempo = boa oportunidade para ficar em casa). Isso porque o valor de $\mathrm{A}$ é determinado pela relação com $\mathrm{C}$. Nas palavras do próprio Ducrot (1988, p. 73, tradução nossa): "Penso que nossas palavras não têm sentido

\footnotetext{
7 "[...] la idea fundamental respecto del sentido: el sentido se basa em la argumentación" (CAREL E DUCROT, 2005, p. 12).
}

completo antes das conclusões que tiramos delas" ${ }^{\text {. A }}$ tese da semântica argumentativa é a de que tanto $A$ quanto C fazem parte de um mesmo enunciado, havendo uma relação de necessidade de um em relação ao outro para completarem seu sentido. A e C são um todo, dividido em duas partes que se interdependem.

A terceira condição para que haja argumentação no discurso, na concepção tradicional, é que $\mathrm{A}$ contém $\mathrm{H}$, e $\mathrm{H}$ implica $\mathrm{C}$ (Se A...., logo C). Essa relação é extralinguística, depende de fatores externos ao sistema linguístico. Percebe-se que a argumentação, na concepção tradicional, está fora da língua, ancorada em algum fato da realidade, em alguma informação, em algum princípio lógico, etc.

Ao contrário da concepção tradicional, a ANL busca o sentido intralinguístico, postulando que a argumentação está na própria língua. Os exemplos apresentados por Ducrot (1988, p.76) "pouco" e "um pouco" servem bem para ilustrar como as entidades linguísticas possuem orientação argumentativa. Dizer "Francisco produziu pouco" possui um valor negativo, enquanto "Paulo produziu um pouco" possui um valor positivo. As palavras significam, a própria língua é em si argumentativa.

A ANL nasce a partir de algumas influências. Bez (2014) aponta os fundamentos filosóficos da ANL: a alteridade de Platão, com a ideia da relação entre o eu e o outro, ou seja, é pela diferença que a semelhança se constitui. Nas palavras dessa autora "cada coisa é constituída pelo que ela é, e por sua diferença, em relação a tudo que ela não é" (BEZ, 2014, p. 29). Outro fundamento para a ANL são as noções de língua, valor e relação de Saussure. A respeito das influências do estruturalismo saussuriano, Carel e Ducrot (2005) esclarecem:

Em termos gerais, pode-se afirmar que a ANL é uma aplicação do estruturalismo saussuriano à Semântica Linguística, na medida em que para Saussure, o significado de uma expressão reside nas relações dessas expressões com as outras expressões da

8 "Pienso que nuestras palabras no tienen sentido completo antes de las conclusiones que sacamos de ellas" (DUCROT, 1988, p. 73). 
língua (CAREL E DUCROT, 2005, p. 11, tradução nossa). ${ }^{9}$

Carel e Ducrot (2005) explicam que as bases da ANL estão nos postulados saussurianos, sobretudo nos aspectos relacionais da língua. A língua, para Saussure (2006), é um sistema de signos. A significação da língua é determinada por relações. No próprio signo há uma relação entre um significante e um significado. Além disso, os signos se relacionam com outros signos para significar. O princípio de valor das entidades linguísticas está justamente na relação entre os signos. Outro aspecto relevante sobre a tese saussuriana, apontado por Carel e Ducrot (2005, p. 11), é de que a significação de um signo independe do referente ou do conceito psicológico que os falantes da língua teriam arquivado na memória. A significação do signo depende das relações entre os próprios signos da língua.

Estes princípios saussurianos influenciaram fortemente a semântica argumentativa, pois a ANL defende que o sistema linguístico, por si só, é capaz de produzir argumentação, independente de aspectos da realidade, como valor de verdade, de informação, etc., ou seja, a ANL procura mostrar que as entidades linguísticas possuem orientação argumentativa. Já que as próprias palavras significam, a argumentação está na própria língua. O sentido dos discursos se dá nas relações dentro do próprio sistema linguístico, independentemente de aspectos extralinguísticos.

Outra base importante para a ANL é a teoria da enunciação de Émile Benveniste. De acordo com Bez, "Benveniste, ao estabelecer o sentido a partir do aparelho formal da enunciação (eu-tu-aqui-agora) confere ao uso da língua fator determinante para sua semantização. (BEZ, 2014, p. 98). A autora explica que, segundo a tese benvenistiana, enunciação é colocar em funcionamento o aparelho formal da enunciação enquanto, segundo Ducrot, enunciação é o aparecimento do enunciado (BEZ, 2014, p.100).
Apesar da divergência nesse conceito de enunciação, a ANL foi fortemente influenciada pela teoria da enunciação benvenistiana, especialmente no que se refere à refutação da concepção tradicional da linguagem, que defendia a objetividade da linguagem, como representação da realidade. Bez (2014) explica que:

É essa concepção tradicional que Ducrot pretende contestar, pois, para ele, a linguagem não é objetiva, nem representa ou descreve a realidade. A partir da linguagem e suas relações subjetivas e intersubjetivas, 0 mundo adquire sentido e é esse sentido o responsável por orientar o discurso. Enquanto a objetividade isenta o locutor de quaisquer responsabilidades, a subjetividade faz com que ele tenha um posicionamento e o direcione para um interlocutor. Dessa forma, quando se tem a presença dos dois seres de fala, não há espaço para a objetividade, mas para a subjetividade e a intersubjetividade, como já afirmava Benveniste no texto em que trata do aparelho formal da enunciação. Assim, no enunciado Pedro é inteligente não temos a descrição da realidade, mas o ponto de vista do locutor sobre Pedro que pede uma atitude do locutor. Torna-se visível que as noções de subjetividade e intersubjetividade advêm de Benveniste, pois Ducrot deixa claro no desenvolvimento de seu trabalho que o sentido emana da relação eu-tu-aqui-agora, em um contexto intralinguístico (BEZ, 2014, p. 99).

Assim, fica bastante claro que os quesitos subjetividade e intersubjetividade, segundo Bez (2014), são bases relevantes da teoria da enunciação benvenistiana e pontos defendidos pela ANL. Tendo explicadas as influências da ANL, passemos para a explicação de suas fases.

Encontramos uma boa síntese das fases da ANL em Bez (2014). Vejamos como essa autora resume essas fases:

\footnotetext{
9 “En términos generales, puede afirmarse que la TADL es uma aplicación del estruturalismo saussuriano a la semántica linguística em la medida em que, para Saussure, el significado de uma expresión reside em las relaciones de esa expresión com otras expresiones de la lengua" (CAREL E DUCROT, 2005, p. 11).
} 
Quadro 1: Fases da ANL

\begin{tabular}{|c|c|c|}
\hline \multicolumn{3}{|c|}{ Teoria da Argumentação na Língua (ANL) } \\
\hline \multicolumn{2}{|r|}{ Fases } & $\begin{array}{l}\text { Breve definição } \text { de } \\
\text { argumentação, em cada } \\
\text { fase, nas palavras de Bez } \\
(2014, \text { p. 19): }\end{array}$ \\
\hline $\begin{array}{c}1 \underline{a} \\
\text { fase }\end{array}$ & $\begin{array}{l}\text { Forma } \\
\text { Standard }\end{array}$ & $\begin{array}{l}\text { "A argumentação é definida } \\
\text { pelas conclusões possíveis." }\end{array}$ \\
\hline $\begin{array}{c}2^{\underline{a}} \\
\text { fase }\end{array}$ & $\begin{array}{l}\text { Standard } \\
\text { Ampliada: } \\
\text { topoi }+ \\
\text { Polifonia }\end{array}$ & $\begin{array}{l}\text { "A argumentação é o } \\
\text { conjunto de topoi que pode } \\
\text { ser } \quad \text { evocado } \\
\text { determinada entidade." }\end{array}$ \\
\hline $\begin{array}{c}3^{\underline{a}} \\
\text { fase }\end{array}$ & $\begin{array}{l}\text { Teoria dos } \\
\text { Blocos } \\
\text { Semânticos }\end{array}$ & $\begin{array}{l}\text { "A argumentação está nos } \\
\text { aspectos argumentativos e } \\
\text { suas relações." }\end{array}$ \\
\hline $\begin{array}{c}4 \stackrel{a}{a} \\
\text { fase }\end{array}$ & $\begin{array}{c}\text { Teoria } \\
\text { Argumentativa } \\
\text { da Polifonia } \\
\text { (uma versão } \\
\text { diferente da } \\
\text { versão da } \\
\text { polifonia da } \\
\text { segunda fase) }\end{array}$ & $\begin{array}{l}\text { "A argumentação depende } \\
\text { da atitude do locutor frente } \\
\text { aos enunciadores." }\end{array}$ \\
\hline
\end{tabular}

Fonte: Elaborado pelos autores com base em Bez (2014, p. 19).

Gostaríamos de destacar que a TBS (terceira fase da ANL) surge após a Teoria dos topoi (segunda fase da $A N L)$, que foi rejeitada pela ANL. De acordo com Bez (2014, p. 158), essa teoria "surgiu da necessidade de explicar o sentido de enunciados que não são evidentes, precisando de contextos específicos para serem compreendidos", tentando "mostrar que não estava ligada a condições de verdade vinculadas à lógica". Primeiramente, é importante compreendermos o que significa topoi. Este termo tem origem grega, compreendido como ponto comum de partida de uma argumentação. Refere-se a "lugares comuns", princípios gerais, fornecidos pela comunidade linguística da qual fazem parte o locutor e interlocutor (BEZ, 2014, p. 159). Ainda segundo essa autora,

[...] os topoi são lugares comuns representados pela passagem do argumento para a conclusão. Esse caminho só pode ser feito através de garantias, termo advindo de Aristóteles em sua obra Tópicos, e após, adaptada por Toulmin em seu modelo de argumentação. Anscombre utilizar-se-á também desse termo em homenagem ao filósofo grego, denominando essas garantias como sendo topoi (BEZ, 2014, p. 159).
Um bom exemplo que trazemos para explicar o que é topoi é o provérbio "time is money" (tempo é dinheiro), comumente atribuído a Benjamim Franklin (1748), que carrega o topos "não se deve perder tempo, deve-se viver agindo rapidamente, pois tempo é um recurso valiosíssimo". Temos aqui um fato linguístico, entretanto ancorado em um princípio, um valor, uma ideologia de uma comunidade linguística, ou seja, um princípio extralinguístico. Faz-se necessário compreendermos esse topos, esse lugar comum, que é compartilhado, pelo menos por um locutor e um interlocutor, para compreendermos o enunciado "time is money".

Bez (2014, p. 159) deixa claro que a Teoria dos topoi refere-se a princípios extralinguísticos, apesar de serem construídos a partir dos fatos linguísticos (formas sentenciosas, como provérbios e ditos, enunciados e léxico). A existência de um topos depende das ideologias de uma comunidade linguística. Isso distancia essa teoria da tentativa da ANL de defender o sentido intralinguístico. A TBS resgata essa tentativa. A Teoria dos topoi foi rejeitada pela ANL por recorrer a aspectos extralinguísticos, contrariando a tese de que a argumentação está na própria língua. Sobre essa mudança de perspectiva na ANL, Carel e Ducrot (2005) afirma:

Marion Carel percebeu que esta teoria [a Teoria dos topoi], na realidade traía a ideia principal da ANL, pois acreditava que a argumentação estava em aspectos existentes no mundo, enquanto o que tentamos defender é que a argumentação é de uma ordem estritamente linguística. É por isso que a tese de Marion Carel (1992) tem sido uma crítica a essa teoria (CAREL E DUCROT, 2005, p. 13, tradução nossa). ${ }^{10}$

A TBS é a fase mais radical da $A N L$, postulando que o próprio sistema linguístico possui entidades com orientação argumentativa, e que são os encadeamentos entre um segmento e outro, ou

\footnotetext{
10 Marion Carel se dio cuenta de que esta teoria [Teoria de los topoi] en realidad traicionaba la idea misma de la TADL, pues basaba la argumentacíon em elementos existentes en el mundo, mientras que lo que intentamos establecer es que la argumentacíon es de orden estrictamente linguístico. Es por eso que la tesis de Marion Carel (1992) há sido uma crítica a esta teoria (CAREL E DUCROT, 2005, p. 13).
} 
seja, a relação entre eles, que produzem o sentido do enunciado.

Elegemos, para análise do nosso corpus, justamente a terceira fase da ANL, ou seja, a TBS, por acreditarmos que é a parte mais fiel da ANL ao sentido intralinguístico.

\section{Teoria dos Blocos Semânticos}

De acordo com Ducrot (1988, p. 82), a tese da ANL é de que a própria língua possui elementos argumentativos. Nas palavras do próprio Ducrot:

A ideia central da teoria da ANL afirma que as argumentações realizadas no discurso estão determinadas pelas frases da língua e que esta argumentação é independente, pelo menos em parte, dos fatos expressos nos enunciados (DUCROT, 1988, p. 98, tradução nossa). ${ }^{11}$

Sendo a língua capaz de produzir argumentação independente de aspectos extralinguísticos, Carel e Ducrot (2005), embasados na tese de Saussure (2006) de que tudo na língua é relação, defendem a ideia de que há relações entre segmentos do enunciado que determinam o seu sentido.

Em primeiro lugar, antes de explicarmos a noção das relações entre os segmentos de um enunciado, Carel e Ducrot (2005, p. 12) ilustram que as próprias palavras significam, com o seguinte exemplo: "meu hotel está perto da universidade", sendo que a conclusão "portanto é fácil chegar" é autorizado não pela informação, mas porque a palavra "perto", em si mesma, significa isso. Essa é uma boa ilustração do sentido intralinguístico defendido pela ANL, reforçada especialmente pela TBS.

Em segundo lugar, Carel e Ducrot (2005, p. 13, tradução nossa) definem a ideia principal da TBS, dizendo que "[...] o sentido de uma entidade linguística não está constituído por coisas, fatos, propriedades, crenças psicológicas, nem ideias. Está

\footnotetext{
11 La idea central de la teoria de la ADL plantea que las argumentationes realizadas em el discurso están determinadas por las frases de la lengua y que esta argumentación es independiente, al menos parcialmente, de los hechos expressados en los enunciados (DUCROT, 1988, p. 98).
}

constituído por certos discursos que esta entidade linguística evoca"12. Os autores nomeiam esses discursos "encadeamentos argumentativos". Para explicar melhor, utilizemos a terminologia dos autores: $\mathrm{X}$ CONECTOR $\mathrm{Y}$. Um discurso ou um encadeamento é formado por dois segmentos ( $\mathrm{X}$ e $\mathrm{Y})$, unidos por um conector. Há dois tipos de conectores: PORTANTO (DC) - conector normativo e NO ENTANTO $(\mathrm{PT})$ - conector transgressivo. É válido salientar que esses conectores podem não se encontrar no enunciado, podendo, contudo, serem evocados na forma, muitas vezes, de outras palavras e expressões, já que a relação normativa ou transgressiva se estabelece de diversas maneiras. Vejamos dois exemplos fornecidos pelos representantes da TBS:

(1) Pedro é prudente, portanto não terá nenhum acidente (X DC Y).

(2) Pedro é prudente, no entanto, sofreu acidentes (X PT Y).

No exemplo 1, há um encadeamento normativo em DC, e no exemplo 2 há um encadeamento transgressivo em PT. É importante notar que um segmento do enunciado só completa o seu sentido com o outro. Esse fato é chamado por Carel e Ducrot (2005, p. 16) de interdependência semântica, conceito introduzido pela TBS. Percebe-se, aqui, a influência saussuriana de língua, enquanto sistema significante, de valor e de relação. Para Saussure (2006), um signo se relaciona com outros signos da língua. $O$ valor das entidades linguísticas é determinado exatamente nessa relação entre os signos. A TBS, com base nesses preceitos saussurianos, defende que os segmentos de um enunciado mantêm uma relação intrínseca com o outro, evocando encadeamentos em DC ou PT para completarem o sentido dos mesmos.

Entretanto, escolhido um conector, há encadeamentos possíveis e encadeamentos

\footnotetext{
12 "[...] el sentido de uma entidade linguística no está constituido por cosas, hechos, propriedades, creencias psicológicas, ni ideas. Está constituido por ciertos discursos que esa entidade linguística evoca" (CAREL E DUCROT, 2005, p. 13).
} 
impossíveis a partir dele. De acordo com Carel e Ducrot (2005, p. 22), isso não significa que as orações sejam incompatíveis em relação às outras, pois a TBS acredita que qualquer oração é compatível com qualquer outra. A questão, segundo os autores, é a escolha do conector correto. Analisemos um exemplo, elaborado por nós, que ilustra bem isso.

(3) Estou com sede, portanto, vou beber água (A DC B).

No exemplo acima, o conector normativo DC não poderia ser substituído pelo conector PT no mesmo bloco semântico. O enunciado "Estou com sede, no entanto vou beber água" parece impossível neste bloco, pois a palavra "sede" possui em si mesma uma orientação argumentativa, cujo sentido é "preciso beber água/ tomar alguma bebida". Contudo, poderíamos perfeitamente dizer "Estou com sede, no entanto não vou beber água”. Este último encadeamento, apesar de ser transgressivo, mantém o mesmo sentido do bloco sede DC beber água.

Carel e Ducrot (2005, p. 22-24) elaboram oito formas de articular os segmentos do enunciado, chamados de encadeamentos argumentativos do bloco semântico, sendo que cada bloco semântico (cada sentido) contém quatro encadeamentos, ou seja, quatro formas/possibilidades de expressar o mesmo sentido de um dado bloco semântico. Vejamos como Cabral (2011) explica isso:

Segundo Carel (2001), a noção de "aspecto" diz respeito à relação que se estabelece entre $\mathrm{X}$ e $\mathrm{Y}$. Em outras palavras, a relação entre duas palavras compreende dois aspectos, ligados à mesma regra, ou, como afirma Negroni (2001), dois aspectos de uma mesma maneira de ver as coisas (CABRAL, 2011, p. 208) [grifos nossos].

Assim, dois segmentos ( $A$ e $B$, ou $X$ e $Y$ ), unidos por um conector, formam um aspecto argumentativo, que é, na verdade, uma "forma de ver" algo. Reiteramos que, neste artigo, estamos tratando de como argumentação - que pressupomos estar na língua - constrói sentidos. Como já dissemos, a depender do conector que utilizamos para unir/encadear diferentes segmentos, diferentes sentidos são construídos. A argumentação pode ser normativa (quando se utiliza o conector DC entre os segmentos) ou por meio de uma argumentação transgressiva (quando se utiliza o conector PT). Conforme Cabral (2011, p. 208), "[...] encadeamentos materialmente diferentes podem realizar o mesmo aspecto; o aspecto constitui um conjunto de encadeamentos de mesmo valor (normativo ou transgressivo)". Essa autora esclarece que o caráter transgressivo é, na verdade, "um outro aspecto de uma mesma regra".

Vejamos os quatro encadeamentos possíveis para o aspecto começar a sentir frio DC vestir um agasalho, exemplo que elaboramos para exemplificar essa questão:

(4) A DC B: Está esfriando, portanto vamos vestir um agasalho.

(5) A PT NEG-B: Está esfriando, no entanto, não vamos vestir um agasalho.

(6) NEG A PT B: Não está esfriando, no entanto, vamos vestir um agasalho.

(7) NEG A DC NEG-B: Não está esfriando, portanto, não vamos vestir um agasalho.

Cada um dos encadeamentos acima faz parte do mesmo bloco semântico, haja vista que todos esses quatro exemplos possuem o sentido: deve-se vestir um agasalho quando começar a fazer frio. Podemos, todavia, construir outro sentido por meio de outro bloco semântico, composto de outros quatro encadeamentos. Imaginemos que um grupo de pessoas acampando em uma floresta acredite que o clima esteja esfriando, entretanto desejam experimentar um pouco desse início da queda da temperatura, que até o momento ainda não é excessivo. Nesse caso, eles evocariam o aspecto começar a sentir frio DC não vestir um agasalho, bloco semântico composto de outros quatro encadeamentos argumentativos. Vejamos essas possibilidades: 
(8) A DC neg-B: Está esfriando, portanto, não vamos vestir um agasalho.

(9) A PT B: Está esfriando, no entanto, vamos vestir um agasalho.

(10) Neg-A DC B: Não está esfriando, portanto vamos vestir um agasalho.

(11) Neg-A PT Neg-B: Não está esfriando, no entanto não vamos vestir um agasalho.

Os exemplos (8), (9), (10), e (11) fazem parte de um mesmo bloco semântico, bloco este que é diferente do bloco anterior, ilustrado pelos exemplos (4), (5), (6) e (7), justamente porque possuem sentidos diferentes. O primeiro bloco semântico evoca - aspecto começar a sentir frio DC vestir um agasalho, enquanto o segundo bloco evoca outro aspecto: começar a sentir frio $D C$ não vestir um agasalho. Carel e Ducrot (2005, p. 31) ressaltam que a interdependência semântica é a mesma dentro do mesmo bloco. Os quatro encadeamentos do mesmo bloco mantêm o mesmo sentido a partir de $\mathrm{A}$ e $\mathrm{B}$, unidos por DC ou PT. Carel e Ducrot (2005) explicam que a interdependência semântica se mostra no fato de que cada um dos segmentos encadeados só ganha sentido em relação com o outro, ou seja, um segmento A só tem o seu sentido completo a partir da relação com $B$. Um depende do outro.

Essa interdependência introduzida pela TBS é linguística, nada tem a ver com fatos da realidade, com a lógica, pois essa teoria defende que a argumentação está na língua e não na passagem do argumento para a conclusão, como defendia a concepção tradicional da argumentação. Para a TBS, não há um fato em $A$ que implique $C$, mas que 0 próprio sistema linguístico é argumentativo. A interdependência da qual tratamos é criada por um elemento linguístico, um conector, que estabelece uma relação entre esses segmentos. A TBS é fase que mais representa a ANL, por eliminar elementos extralinguísticos da teoria e defender o sentido intralinguístico.

Passemos, agora, à análise do nosso corpus.

\section{Análise do debate}

De acordo com a TBS, o sentido de uma expressão ou de um enunciado está nos encadeamentos que eles evocam (CAREL E DUCROT, 2005, p. 29). Pretendemos, com a análise seguinte, perceber os encadeamentos evocados pelo discurso, compreendendo seu sentido, a partir da própria língua e suas relações. Para ilustrar o sentido intralinguístico nos encadeamentos argumentativos, defendido pela TBS, escolhemos o seguinte corpus para nossa análise, conforme já dissemos, na introdução: um debate entre os deputados federais Ronaldo Fonseca (PROS) e Jean Wyllys (PSOL). O tema do debate é o Estatuto da Família, criado pelo PL 6.583/13, que objetiva definir a família no Brasil como a união entre um homem, uma mulher e os filhos, excluindo a união homoafetiva desse conceito. Trata-se de um texto oral, de doze minutos, o qual baixamos da internet, do portal Youtube.

Após termos concluído o download do debate, utilizamos o programa Elan (que auxilia na transcrição de vídeo), para realizar uma transcrição ortográfica, que é mais simples - por não ser uma transcrição fonética, que envolve símbolos mais complexos. Além disso, não é nosso objetivo, nesse estudo, analisar aspectos fonológicos. Após essa etapa, elegemos excertos do discurso de cada deputado que melhor ilustram o sentido defendido por cada um durante o debate. Nossa intenção é apontar o aspecto argumentativo evocado pelo discurso de cada um dos debatedores. A partir disso, montaremos o bloco semântico defendido por cada deputado, separadamente, com os quatro encadeamentos de cada bloco (que possuem a mesma interdependência semântica. Após essa etapa, também para cada deputado, separadamente, montaremos o bloco semântico que possui o sentido oposto ao que cada um defende. No total, teremos dois blocos semânticos para cada deputado, sendo que cada bloco semântico possui quatro possibilidades de encadeamentos, conforme a TBS.

Iniciemos com dois excertos que ilustram o discurso evocado pelo Deputado Ronaldo Fonseca, quando defende que o conceito de família deve ser 
compreendido como a união entre um homem, uma mulher e os filhos.

"Bom, o que nós temos hoje na Constituição Federal é muito claro: artigo 226 da Constituição Federal e artigo 1514 do Código Civil. Está claro: o casamento ou a união estável, o casamento civil ou a união estável deve ser entre um homem e uma mulher. Está muito claro na legislação. O que nós temos de legislação hoje é isto que eu disse, está claro, a base é esta. O casamento civil ou a união estável é entre o homem e a mulher. Isto é o que está na Constituição Federal e nas leis infraconstitucionais."

"Agora... além, além da questão legal nós temos a questão natural, uai, eu entendo como família constituído o núcleo familiar por papai, homem, mamãe, mulher, e esta é questão natural, esta é questão natural, a natureza já diz isto, que é um homem e uma mulher, o que estiver fora disto está um outro padrão".

O discurso do deputado evangélico evoca diversos aspectos argumentativos. Primeiramente, Ronaldo Fonseca evoca o aspecto relação heterossexual DC casamento ou união estável, que é um aspecto intermediário antes de um outro: união heterossexual DC amparo da lei. Vejamos as possibilidades de encadeamentos a partir deste último aspecto:

(12) A DC B: A união é heterossexual, portanto é amparada pela lei.

(13) A PT NEG-B: A união é heterossexual, no entanto não é amparada pela lei.

(14) NEG A PT B: A união não é heterossexual, no entanto é amparada pela lei.

(15) NEG A DC NEG-B: A união não é heterossexual, portanto não é amparada pela lei.

O aspecto união heterossexual DC amparo da lei fundamenta-se, no discurso de Ronaldo Fonseca, no seguinte aspecto: união entre homem e mulher $D C$ questão natural. Esses dois aspectos trazem à tona dois conceitos: o conceito de família embasado na legislação e o conceito de família embasado na questão biológica. Ronaldo Fonseca evoca o discurso que defende que o correto é a união entre um homem e uma mulher, e que este conceito embasado na biologia tem amparo legal no Brasil. Para esse deputado, o conceito de família baseado na questão biológica deve excluir outros conceitos.

Assim, os encadeamentos argumentativos (12), (13), (14) e (15) formam um bloco semântico, cujo sentido é: a lei deve amparar as uniões heterossexuais. Este é o sentido defendido pelo deputado pastor. O bloco semântico com sentido oposto seria:

(16) A DC Neg B: A união é heterossexual, portanto não é amparada pela lei.

(17) A PT B: A união é heterossexual, no entanto é amparada pela lei.

(18) Neg A DC B: A união não é heterossexual, portanto é amparada pela lei.

(19) Neg A PT Neg B: A união não é heterossexual, no entanto, não é amparada pela lei.

Os encadeamentos (16), (17), (18) e (19) foram elaborados a partir do seguinte aspecto: relação heterossexual DC não-amparo da lei, ou seja, o sentido desse bloco semântico é a lei não deve acolher as relações heterossexuais, sentido este que é oposto ao defendido pelo Deputado Ronaldo Fonseca durante o debate.

Agora, vamos analisar os encadeamentos argumentativos evocados pelo Deputado Jean Wyllys. Para compreendermos melhor o sentido de seu discurso, escolhemos os seguintes excertos de sua fala durante o debate:

"[...] é importante lembrar que todos os ministros do STF votaram a favor do reconhecimento da entidade familiar homoafetiva, eles usaram os princípios da Constituição que são superiores ao artigo 226, que é o princípio da dignidade humana, que tá no artigo 1, o princípio que veda a discriminação de qualquer tipo que tá no artigo 5o se eu não me engano, é... não..., o do artigo 5ํ tá o princípio da igualdade, e os objetivos da república que diz sim, que é do Estado o dever de promover o bem de todos sem discriminação de qualquer tipo." 
"É dever da República promover o bem de todos sem discriminação de qualquer natureza: de sexo, de identidade, de gênero, de orientação sexual, de procedência, ou seja, o Estado não tem que se colocar contra o objetivo das pessoas de fazer um projeto de vida baseada no afeto e esse Estatuto da Família faz isso".

Os dois excertos acima evocam alguns aspectos importantes. O primeiro que destacamos é princípio de dignidade humana DC não-discriminação de qualquer tipo. O segundo aspecto evocado no discurso de Jean Wyllys é princípio de igualdade $D C$ promoção do bem de todos pelo Estado. Esses dois aspectos argumentativos intermediários nos conduzem a um outro aspecto que consideramos o principal na discussão de Jean Wyllys, a saber: dever da República de promover o bem de todos DC nãoboicote ao objetivo das pessoas que desejam construir uma família baseada no afeto. Vejamos os encadeamentos argumentativos possíveis nesse bloco semântico:

(20) A DC B: A República deve promover o bem de todos, portanto aceita o objetivo das pessoas que desejam construir uma família baseada no afeto.

(21) A PT NEG-B: A República deve promover o bem de todos, no entanto não aceita o objetivo das pessoas que desejam construir uma família baseada no afeto.

(22) NEG A PT B: A República não deve promover o bem de todos, no entanto aceita o objetivo das pessoas que desejam construir uma família baseada no afeto.

(23) NEG A DC NEG-B: A República não deve promover o bem de todos, portanto não aceita o objetivo das pessoas que desejam construir uma família baseada no afeto.

Os encadeamentos argumentativos (20), (21), (22) e (23) fazem parte do bloco semântico evocado pelo deputado progressista: o Estado brasileiro tem o dever de promover o bem de todos, portanto aqueles que desejam construir uma família baseada no afeto têm esse direito. Jean Wyllys defende que os casais homoafetivos não podem ser excluídos do princípio constitucional do direito à liberdade de escolha, que nesse caso é a escolha do tipo de família que eles desejam construir. Esse deputado discute um terceiro conceito de família que não está embasado na questão biológica, nem na questão legal trazida pelo Artigo 1514 do Código Civil de 2002 ou no artigo 226 da Constituição Federal de 1988, mas no afeto, no amor entre as pessoas e no desejo delas de construírem uma família. Esse conceito pode abarcar outras configurações familiares, contudo, as uniões homoafetivas ganham o centro da discussão no debate. Jean Wyllys argumenta que a Carta Magna possui princípios superiores aos artigos mencionados (que amparam a família heteronormativa) e que esses princípios acolhem o conceito de família que ele defende (a família homoafetiva).

Observemos, no bloco semântico abaixo, como o sentido oposto pode ser construído a partir do aspecto dever da República de promover o bem dos heterossexuais DC boicote ao objetivo das pessoas que desejam construir uma família baseada no afeto. Vejamos as possibilidades de encadeamentos no bloco semântico contrário ao defendido pelo deputado do PSOL:

(24) A DC Neg B: A República deve promover o bem dos heterossexuais, portanto não aceita o objetivo das pessoas que desejam construir uma família baseada no afeto.

(25) A PT B: A República deve promover o bem dos heterossexuais, no entanto aceita o objetivo das pessoas que desejam construir uma família baseada no afeto.

(26) Neg A DC B: A República não deve promover o bem dos heterossexuais, portanto aceita o objetivo das pessoas que desejam construir uma família baseada no afeto.

(27) Neg A PT Neg B: A República não deve promover o bem dos heterossexuais, no entanto não aceita o objetivo das pessoas que desejam construir uma família baseada no afeto. 
O bloco semântico composto pelos encadeamentos argumentativos (20), (21) (22) e (23) possui um sentido diferente, oposto ao bloco composto pelos aspectos (24), (25), (26) e (27). Neste último, é evocado o aspecto dever da República de promover o bem dos heterossexuais DC boicote ao objetivo das pessoas que desejam construir uma família homoafetiva. Vimos que o deputado do PSOL pensa exatamente o contrário, ao evocar o primeiro bloco semântico, acreditando que se é dever da República brasileira promover o bem de todas as pessoas, os homoafetivos não podem ter seu bemestar negado e, por isso, podem decidir construir uma família baseada no afeto. O deputado defende que o Estatuto da Família proposto pela bancada evangélica do Congresso Nacional é inconstitucional por ser discriminatório.

\section{Considerações finais}

Com a análise de um debate entre os deputados federais Ronaldo Fonseca e Jean Wyllys, à luz da TBS, percebemos que o discurso evoca encadeamentos que constituem o sentido dos enunciados. Em cada bloco semântico, há quatro encadeamentos argumentativos que mantêm o mesmo sentido do bloco. Dois segmentos de um enunciado, unidos pelos conectores DC ou PT, mantém uma interdependência semântica, em que um segmento depende do outro para completar seu sentido. Essa relação é linguística, influenciada pela alteridade platoniana e pelo estruturalismo saussuriano, especificamente pelos princípios de relação e valor e pela Teoria da Enunciação de Émile Benveniste.

Os encadeamentos argumentativos postulados pela ANL, especificamente na fase da TBS, e a qual analisamos em nosso corpus, ilustram que a língua possui orientação argumentativa e que as relações entre as entidades linguísticas produzem argumentação e sentido, fazendo-nos concluir que a língua não é utilizada pelos seres humanos para representar a realidade, mas para criar realidades, para criar pontos de vista sobre o mundo, para criar sentidos diversos por meio do discurso.

\section{Referências}

ANSCOMBRE, Jean-Claude; DUCROT, Oswald. L'argumentation dans la langue. Paris: Mardaga, 1983.

BEZ, Alessandra da Silveira. Fundamentos filosóficos da teoria da argumentação na língua: um estudo sobre a teoria dos topoi e a teoria dos blocos semânticos. 2014. 244 f. Tese (Doutorado em Letras) - Programa de Pós-Graduação em Letras, Pontifícia Universidade Católica do Rio Grande do Sul, Porto Alegre, 2014.

CABRAL, A. L. T. Contribuições da Teoria da Argumentação na língua para o ensino de leitura. Linha d'Agua, São Paulo, v. 24, n.2, p. 205-215, 2011.

CAREL, Marion; DUCROT, Oswald. La Semántica Argumentativa. Una Introducción a la Teoría de los Bloques Semánticos. Edición literaria a cargo de María Marta Negroni y Alfredo M. Lescano. Buenos Aires: Colihue, 2005.

CRISTOVÃO, V. L. L.; DURÃO, A. B. A. B.; NASCIMENTO, E. L. Debate Em Sala de Aula: Práticas de Linguagem em um Gênero Escolar. In: 5ํㅡㄹ Encontro do CelSul, 2003, Curitiba. Anais do $5^{\circ}$ Encontro do CelSul, 1966. p. 1436-1441.

DUCROT. Oswald. Polifonía y argumentación: conferencias del seminario "Teoría de la Argumentación y Análisis del Discurso”. Cali: Universidad del Valle, 1988.

FRANKLIN, Benjamin. Advice to a Young Tradesman, [21 July 1748], Founders Online, National Archives. Disponível em $<$ http://founders.archives.gov/documents/Franklin/ 01-03-02-0130> Source: The Papers of Benjamin Franklin, vol. 3, January 1, 1745, through June 30, 1750, ed. Leonard W. Labaree. New Haven: Yale University Press, 1961, pp. 304-308. Acesso em 16 mai. 2016.

SAUSSURE, Ferdinand de. Curso de Linguística Geral. 27. ed. São Paulo: Cultrix, 2006.

SCHNEUWLY, Bernard. DOLZ, Joaquim. Os gêneros escolares: das práticas de linguagem aos objetos de ensino. Revista Brasileira de Educação. 1999. N.11, mai/ jun/ju/ago. Disponível em $<$ http://www.academia.edu/1595337/Os g\%C3\%A Aneros escolares Das pr\%C3\%A1ticas de lingu agem aos objetos de ensino $>$ Acesso em 15 set. 2015. 


\section{COMO CITAR ESSE ARTIGO}

LOPES, Marildo de Oliveira; PEREIRA, Márcia Helena de Melo; DA SILVA, Adilson Ventura. A CONSTRUÇÃO DE SENTIDOS PELA ARGUMENTAÇÃO NA LÍNGUA: BLOCOS SEMÂNTICOS EM UM DEBATE SOBRE O ESTATUTO DA FAMÍLIA. Signo, Santa Cruz do Sul, v. 42, n. 73, jan. 2017. ISSN 1982-2014. Disponível em: $<$ https://online.unisc.br/seer/index.php/signo/article/view/7878>. Acesso em: doi: http://dx.doi.org/10.17058/signo.v42i73.7878. 